\title{
AS DISPUTAS EDITORIAIS NO CAMPO DO PROGRAMA DO LIVRO DIDÁTICO PARA O ENSINO FUNDAMENTAL DO INSTITUTO NACIONAL DO LIVRO - PLIDEF/INL (1971-1976)
}

DOI: http://dx.doi.org/10.1590/2236-3459/62002

\author{
Mônica Maciel Vahl \\ University of Canterbury, New Zealand. \\ Eliane Peres \\ Universidade Federal de Pelotas, Brasil.
}

\section{Resumo}

Neste artigo se analisa as disputas que envolveram o Programa do Livro Didático para o Ensino Fundamental do Instituto Nacional do Livro - Plidef/INL - e o mercado editorial durante os anos de 1971 a 1976. Para tanto foi utilizado o referencial teórico de campo de Bourdieu (1989, 1994, 1997, 2003). Os dados da pesquisa foram coletados em documentos oficiais e escolares, reportagens em periódicos e livros didáticos. Os resultados indicam a presença de trinta e seis editoras no Programa, contudo, apenas nove publicaram mais de $70 \%$ dos títulos. Os resultados também identificam várias estratégias de difusão dos livros como distribuição gratuita, promoção de concursos e realização de cursos de formação para professores.

Palavras-chave: Instituto Nacional do Livro, livro didático, mercado editorial.

\section{THE EDITORIAL DISPUTES IN THE FIELD OF THE TEXTBOOK PROGRAM FOR} ELEMENTARY EDUCATION OF THE NATIONAL BOOK INSTITUTE - PLIDEF/INL (1971-1976)

\begin{abstract}
This article analyses the disputes involving the Textbook Program for Elementary Education of the National Book Institute - Plidef/INL - and the publishing market during the years 1971 and 1976. For this purpose, the theoretical field framework of Bourdieu $(1989,1994,1997,2003)$ was used. The data were collected in government and school documents, articles in periodicals, and textbooks. The results indicate the presence of thirty-six publishing houses in the Program; however, only nine published more than $70 \%$ of titles. The results also identify various strategies employed for dissemination of the books, such as free distribution, promotional contests, and completion of training courses for teachers.

Key-words: National Book Institute, textbook, publishing market.
\end{abstract}




\section{LAS DISPUTAS EDITORIALES EN EL CAMPO DEL PROGRAMA DEL LIBRO DIDÁCTICO PARA LA ENSEÑANZA FUNDAMENTAL DEL INSTITUTO NACIONAL DEL LIBRO - PLIDEF/INL (1971-1976)}

\section{Resumen}

Este artículo analiza las disputas que envolvieron el Programa del Libro Didáctico para la Enseñanza Fundamental del Instituto Nacional del Libro - Plidef/INL - y el mercado editorial durante los años 1971 y 1976. Para ello, fue usado el referente teórico de campo de Bourdieu (1989, 1994, 1997, 2003). Los datos de la investigación fueron colectados de documentos oficiales y escolares, reportajes de periódicos y libros didácticos. Los resultados indican la presencia de treinta y seis editoriales en el Programa, con todo, apenas nueve publicaron más del $70 \%$ de los títulos. Los resultados también identifican varias estrategias de difusión de los libros como la distribución gratuita, promoción de concursos y ejecución de cursos de formación de profesores.

Palabras-clave: Instituto Nacional del Libro, libro didáctico, mercado editorial.

\section{LES CONFLITS ÉDITORIAUX DANS LE DOMAINE DU PROGRAMME DES MANUELS POUR L'ÉCOLE ÉLÉMENTAIRE DE L'INSTITUT NATIONAL DU LIVRE (1971-1976)}

\section{Résumé}

Cet article analyse les conflits impliquant le Programme des Manuels pour l'École Élémentaire de I'Institut National du Livre et le marché de l'édition pendant les années 1971-1976. Dans ce but, le cadre théorique utilisé a été basé sur la notion de champ de Bourdieu (1989, 1994, 1997, 2003). Les données de la recherche ont été recueillies à partir de documents officiels et scolaires, d'articles de périodiques et de manuels scolaires. Les résultats indiquent la présence de trente-six éditeurs dans le Programme, cependant, seulement ont publié plus de $70 \%$ des titres. Les résultats identifient aussi plusieurs stratégies de diffusion des livres, comme la distribution gratuite, la promotion de concours et de cours de formation pour les enseignants.

Mots-clé: Institut National du Livre, manuels, marché de l'édition. 


\section{Introdução}

ste artigo tem como objetivo analisar as disputas que envolveram o Programa do Livro Didático para o Ensino Fundamental do Instituto Nacional do Livro Plidef/INL - ${ }^{1}$ e o mercado editorial a partir do referencial bourdieusiano de campo (Bourdieu, 1989, 1994, 1997, 2003). Dessa maneira, o Plidef/INL foi compreendido como sendo "ao mesmo tempo como campo de forças e campo de lutas que visam transformar esse campo de forças" (Bourdieu, 1994, p. 44).

Os dados da pesquisa foram obtidos em diferentes fontes, tais como: Diário Oficial da União $^{2}$, documentos do Ministério da Educação e Cultura - MEC - e do INL, reportagens dos periódicos Folha de São Paulo, Jornal do Brasil, Diário de Notícias, Diário do Paraná, O Estado de Mato Grosso e Veja ${ }^{3}$, livros didáticos e documentos escolares.

Para uma melhor compreensão da análise empreendida, o artigo foi organizado em quatro seções. Na primeira identifica-se o funcionamento do Plidef/INL, bem como apresenta a participação das editoras no programa e analisa o posicionamento dos principais agentes editoriais. Na segunda seção discutem-se as diferentes estratégias utilizadas para aumentar a divulgação e venda dos livros didáticos. Na terceira seção aborda-se as controvérsias em relação à coleção de livros integrados Proler e a transferência da gerência do Plidef/INL para a Fundação Nacional do Material Escolar Fename. Por fim, são feitas algumas considerações sobre o mercado editorial e o papel dos livros didáticos na educação brasileira.

\section{O Plidef/INL e as editoras}

O Plidef/INL funcionava por meio de um sistema de coedição que integrava o INL, as secretarias estaduais de Educação - SECs -, as editoras e as distribuidoras. A primeira etapa de funcionamento era o encaminhamento dos livros pelas editoras para o INL. O material recebido era avaliado pelo Departamento do Ensino Fundamental do Ministério da Educação e Cultura. Após a avaliação era remetida uma lista dos livros aprovados para as SECs. As secretarias de Educação, então, indicavam quais as obras se adequavam aos seus programas estaduais. Posteriormente eram realizados estudos de preço e de tiragem por parte do INL. Por fim eram assinados os contratos com as editoras, posteriormente impressos os materiais aprovados e distribuídos os livros nas unidades da federação (MEC/INL. Programa Nacional do Livro Didático, 1973).

A seguir, na figura 1, mostra-se a reprodução de uma chamada para o recebimento de livros para o ensino de $1^{\circ}$ Grau pelo Instituto, publicada no Jornal do Brasil em 1974.

\footnotetext{
${ }^{1}$ O Plidef/INL esteve em vigência entre os anos de 1971 a 1976. Após 1976 o Plidef continuou existindo, mas passou a ser coordenado pela Fundação Nacional do Material Escolar - Fename. Em 1983 o Programa foi incorporado à Fundação de Apoio ao Estudante - FAE. Dois anos mais tarde, em 1985, o Plidef foi extinto com a criação do Programa Nacional do Livro Didático - PNLD.

${ }^{2}$ O DOU foi consultado por meio do website JusBrasil <http://www.jusbrasil.com.br>.

${ }^{3}$ Os dados relativos aos periódicos foram coletados de forma virtual peloss portais da Hemeroteca Digital Brasileira <http://bndigital.bn.br/hemeroteca-digital>, do Grupo Folha <http://acervo.folha.com.br>, e do Grupo Abril <http://veja.abril.com.br/acervodigital>.

\begin{tabular}{|l|l|l} 
Hist. Educ. (Online) & Porto Alegre & v. 20
\end{tabular}

\begin{tabular}{l|l|l} 
v. 20 & n. 50 & Set./dez., 2016
\end{tabular}

p. $219-241$
} 
Figura 1 -

Edital MEC/INL.

\section{AVISO}

\section{MINISTÉRIO DA EDUCAÇÃO E CULTURA INSTITUTO NACIONAL DO LIVRO}

A Diretoria do Instituto Nacional do Livro baixou a Portaria de n. 099 , de 18.02.74, fixando em Crs 250,00 (duzentos e cinquenta cruzeiros) a taxa de avaliaçáo, por volume, das obras do PLIDEF 74/75. cujo pagamento só poderá ser feito em cheque comprado, através do Banco de Brasil S/A, pagável ao Fundo Nacional do Desenvolvimento da Edueaçáo - Conta n.0 188.856/0.

Os criterios pard recebimento dos livros do referido programa são os seguintes:

- Época de recebimento dos livros: 1.0 15 de marso de 1974.

2 - Taxa de inscriçào (para pagamento da avaliação) Cr\$250,00 (duzentos e cinquenta cru. zeiros) - por volume/componente curric.

3 - Livros possiveis de coedição (Série/componenies curriculares)

$10^{\circ}$ a $4 .^{\circ}$ séries do ensuno de $10^{\circ} \mathrm{grau}$ - antigo primário Comunicaça e Expressao e linguagem

- Maremática

- Integraçao Social e Estudos Socidis

- Iniciacao a Ciéncia e Ciêneias Naturais Educaçao Moral e Civica

5a. 8a. séries do ensino de $1.0 \mathrm{grau}$ a antigo ginasio

- Comunicasao cm lingua Portuguesa e Portugués

- Matemática

- Estudos Sociais e Geografia e História e OSPB

- Ciencias a Ciéncias fisicas e Biologicas Educaçáo Moral e Civica

4 Crinerios basicos para selesão dos livros:

$A^{*}$ A obra deve ser livro-texio

B - O livro náo deve versar apenas sobre conhecimentos ou habilidades de uma área especifica

C - O livro deve destinar.se a alunado do ensino de $1.0^{\circ}$ grau.

5 - Outras informaşōes complementares:

A - Todas as obras para as quass se protendo coediçào, no PLIDEF 74/75, deverảo ser avoliadas, independentemente de terem sido incluidas ou nao, em relaşoes oficiais de programas anteriores.

B - Os livros submetidos a avaliaçảo em originais (arte final, em prova ou datilografados), estaráo sujeitos aos prejuizos decorrentes de seu eslágto editoriol, em que mulios dos elementos de avalışáo estaráo ausentes.

C. Somente serdo recebidos livros que vierem acompanhados do respectivo manual do protessor

D. Serao, ande, preferidas pare coedlişáo, as obras quẹ formarem uma coleçáo $\left(1\right.$ a $^{\text {a }}$ 8 a scries) iá completa, ou em processo de preparaşa.

E. En relaşáo aos livros de $1{ }^{a}$ série, a coed.çáo visará a provimento equillibrado de livios de diferenies processos de alfabelizoşao.

Fonte: Jornal do Brasil, 28 fev. 1974, p. 14. 
A chamada acima definia o prazo de recebimento dos livros pelo Instituto, a primeira quinzena de março de 1974, e a taxa de inscrição por volume/componente curricular, no valor de $\operatorname{Cr} \$ 250,00$, o que representava cerca de $66 \%$ do salário mínimo daquele ano ${ }^{4}$. Eram passíveis de coedição livros de $1^{a}$ a $8^{a}$ série, tendo preferência as obras que formassem uma coleção. Também era destacado o "provimento equilibrado de livros de diferentes processos de alfabetização" no que diz respeito aos títulos de Linguagem para a $1^{\circ}$ série, demonstrando uma preocupação por parte do INL com a diversificação dos métodos de alfabetização nesse período (Jornal do Brasil, 28 fev. 1974, p. 14).

Os livros recebidos pelo INL eram avaliados pelo Departamento de Ensino Fundamental do MEC e as listas com as obras aprovadas enviadas para as SECs. A partir do momento em que as SECs deliberavam sobre os títulos e encaminhavam os pedidos para o INL era realizada uma previsão das tiragens de cada livro e a negociação de preço com as editoras. O INL pressionava para a diminuição do preço de capa e utilizava como barganha a compra de um grande número de exemplares. No que se refere ao acerto do preço dos livros didáticos, José Otávio Bertaso ${ }^{5}$ reclamou das comissões de compra posteriores à Comissão do Livro Técnico e Livro Didático - Colted ${ }^{6}$ :

Tomavam como parâmetro a negociação com uma editora que possuísse cinquenta ou mais títulos, todos com apreciáveis tiragens e reduzido número de páginas. A partir daí, estabeleciam um preço médio. Isso tornava muito difícil a negociação com editores que tinham, como nós, poucos títulos para negociar, cada um deles com o dobro de páginas da média previamente negociada. Em consequência disso, negociações que no passado levavam uma hora para ser concluídas passaram a se arrastar durante vários dias. (Bertaso, 1993, p. 226)

As editoras de maior porte no setor dos didáticos e que possuíam, de forma consequente, um número de títulos mais elevado para negociar com INL, recebiam vantagens e podiam estabelecer o preço médio do exemplar. As editoras de porte menor precisavam se adaptar e aceitar margens de lucro que nem sempre eram tão vantajosas. É possível observar a dimensão da importância do preço dos livros didáticos na fase de fechamento de contratos na citação abaixo:

O livro mais solicitado entre os 263 aprovados pelo Departamento de Ensino Fundamental do Ministério da Educação foi Circo do Carequinha, uma cartilha da Editora Vega. As edições da Editora Vigília são as mais solicitadas pelas Secretarias de Educação de vários Estados [...]. Na fase inicial de contratos, o Instituto Nacional do Livro escolheu as obras que ficaram mais baratas, entre as solicitadas, sendo estas das Editoras Agir, Bloch, Abril, Vigília, Lemi, Tabajara e Vega, com as quais os contratos já foram assinados. O mais barato foi $O$ Presente, da escritora Magda

\footnotetext{
${ }^{4}$ Foi utilizado como base para o cálculo o valor do salário mínimo dos meses de maio a dezembro de 1974 , o maior do período. Fonte: Pró-reitoria de Administração e Finanças da Universidade Estadual de Londrina. Disponível em: <http://www.uel.br/proaf/informacoes/indices/salminimo.htm>. Acesso em 17 out., 2015.

5 José Otávio Bertaso foi um dos filhos de Henrique Bertaso, fundador da Editora Globo de Porto Alegre. Durante seus anos de trabalho na Editora José Otávio esteve envolvido na edição de livros didáticos.

${ }^{6}$ A Colted funcionou por meio de um convênio entre o MEC, o Sindicato Nacional dos Editores de Livros Snel - e a Agência dos Estados Unidos para o Desenvolvimento Internacional - Usaid -, entre os anos de 1966 e 1971, e tinha como um de seus objetivos a produção de altas tiragens de livros didáticos.
}

\begin{tabular}{|l|l|l|l|l|}
\hline Hist. Educ. (Online) & Porto Alegre & v. 20 & n. 50 & Set./dez., $2016 \quad 219-241$
\end{tabular} 
Rocha $^{7}$ e publicado pela Editora Agir, custando $\mathrm{Cr} \$ 1,80$. Os mais caros são os das Editoras IBPE, Ao Livro Técnico, Edart e Nacional, cujos contratos estão sendo decididos nesta fase final (Jornal do Brasil, 9 out., 1972, p. 4)

Conforme a reportagem do Jornal do Brasil o INL teria concluído, em primeiro lugar, os contratos com as editoras Agir, Bloch, Abril, Vigília, Lemi, Tabajara e Vega, que possuiriam um catálogo de obras mais baratas no ano de 1972. As editoras com os livros mais caros - IBPE, Ao Livro Técnico, Edart e Companhia Editora Nacional - estariam em compasso de espera para a finalização dos contratos.

É importante salientar que a lista de livros indicados pelas SECs não era, necessariamente, respeitada em sua integralidade por parte do INL. As coedições eram reavaliadas em função do preço e as escolhas eram realizadas entre o repertório de livros didáticos propostos pelas SECs considerando, principalmente, o quesito valor do exemplar.

A partir dos catálogos do INL foi possível produzir um banco de dados sobre os livros coeditados e, desse modo, realizar um mapeamento da participação das editoras no Plidef/INL (1971-1976). Tendo como base o número de títulos coeditados, pelo gráfico que segue apresenta-se a porcentagem de participação de cada editora no programa.

${ }^{7}$ Apesar do artigo do Jornal do Brasil indicar a publicação da cartilha O presente por Magda Rocha, o livro editado pela Agir tem autoria de Magdala Lisboa Bacha. 
Gráfico 1 -

Participação das editoras no Plidef/INL em porcentagem de títulos.

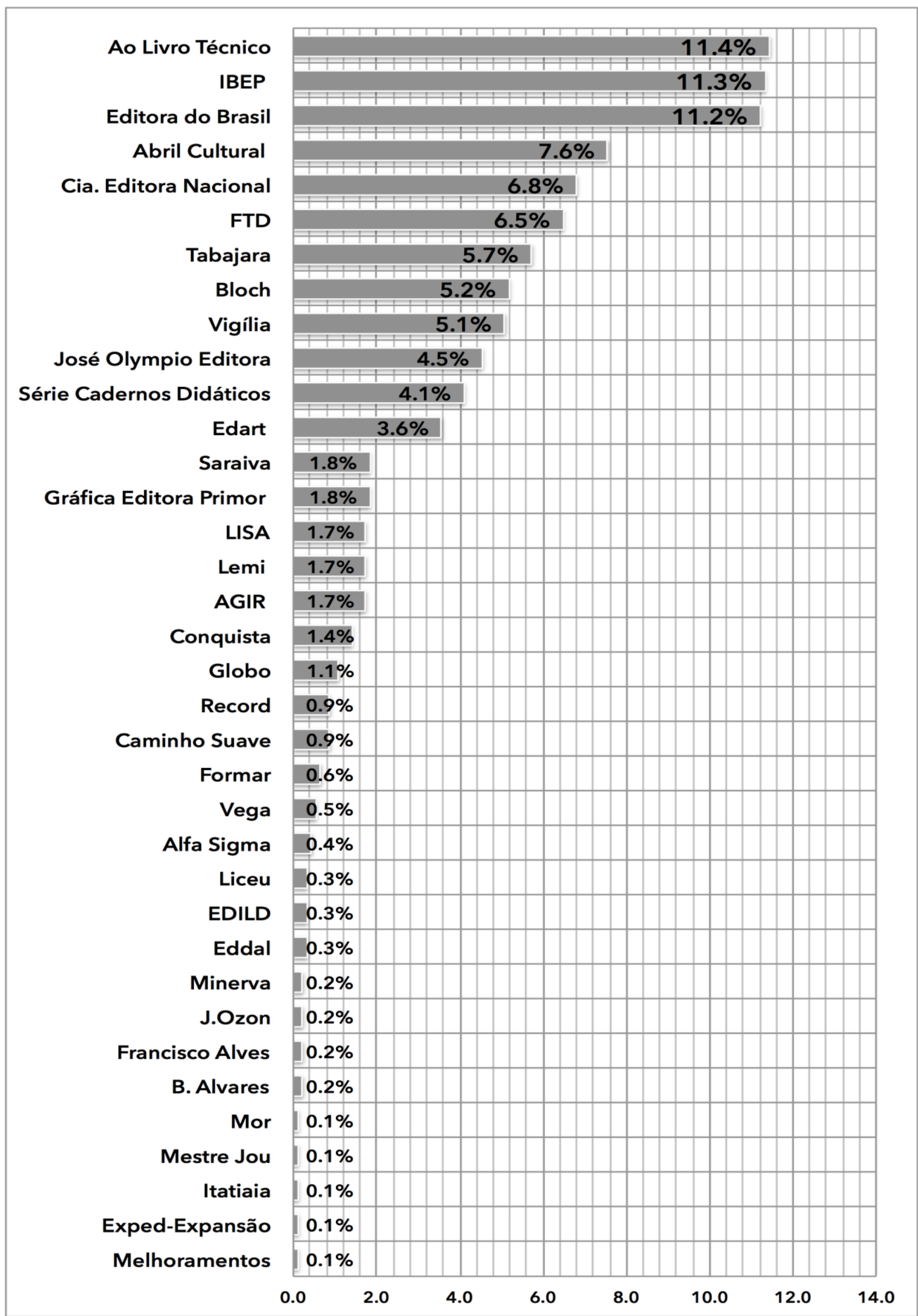

Fonte: Elaborada a partir dos catálogos do INL (MEC/INL, 1974; 1976). 
A partir dos dados compilados percebe-se a participação de 36 editoras no Plidef/INL no período de 1971 a 1975. Dentre esse grupo destaca-se a presença das editoras Ao Livro Técnico, com cento e seis títulos; Ibep, com cento e cinco títulos; Editora do Brasil, com cento e quatro títulos, Abril Cultural, com setenta títulos; Companhia Editora Nacional, com sessenta e três títulos; FTD, com sessenta títulos; Tabajara, com cinquenta e três títulos; Bloch, com quarenta e oito títulos; Vigília, com quarenta e sete títulos. A reunião dessas nove editoras representa a produção de mais de $70 \%$ dos títulos coeditados pelo Plidef/INL no período em questão.

Sobre as estratégias de conservação e subversão de um campo, Bourdieu (2003) salienta que

num campo, e trata-se da lei geral dos campos, os detentores da posição dominante, aqueles que têm mais capital específico, opõem-se sob uma grande multiplicidade de aspectos aos detentores de participações mais recentes (e é deliberadamente que recorro a esta formulação tomada de empréstimo à economia), aos recém-chegados, aos que chegam tarde, aos que chegam de fora e que não possuem muito capital específico. Os antigos participantes tem estratégias de conservação cujo objetivo é extrair ganhos de um capital progressivamente acumulado. Os participantes mais recentes tem estratégias de subversão orientadas para uma acumulação de capital específico que supõe uma inversão mais ou menos revolucionário dos princípios de produção e de apreciação dos produtos e, no mesmo lance, uma desvalorização do capital detido pelos dominantes. (Bourdieu, 2003, p. 207)

Enquanto as nove principais editoras em número de títulos - Ao Livro Técnico, Ibep, Editora do Brasil, Abril Cultural, Companhia Editora Nacional, FTD, Tabajara, Bloch e Vigília - possuíam estratégias de conservação da estrutura do campo, as editoras recém chegadas no campo do Plidef/INL e, portanto, de menor representatividade, como, por exemplo, Eddal, Edild, Liceu, B. Alvares, J.Ozon, Minerva, Exped-Expansão, Itatiaia, Mestre Jou, Mor, que produziram apenas de um a três títulos e juntas representavam somente $2,2 \%$ das coedições, precisavam modificar a lógica de produção dos livros didáticos para ocuparem melhores posições no campo. Ainda existiam as editoras que chegaram tarde, a exemplo da Francisco Alves, que coeditou dois títulos, e pela Melhoramentos, que coeditou somente um título pelo programa.

No caso da Francisco Alves percebeu-se certo descompasso entre as ações da editora e a proposta do programa, que pode ser percebido pela crítica amarga do diretorpresidente da Francisco Alves, almirante Macedo Soares Guimarães. Referia-se ao fato de serem somente os livros coeditados "adotados nas escolas de ensino oficial do Brasil afora", pois nas turmas em que os alunos recebiam parte da tiragem do Instituto dificilmente o professor teria a liberdade de escolher outro título. Além disso, o DiretorPresidente da Francisco Alves reclamava do aparecimento de editoras de um livro só, que surgiam apenas para se beneficiarem do programa do INL, e previa a transformação das editoras privadas em "meras subsidiárias do INL" (Jornal do Brasil, 17 mar. 1974, p. 26) ${ }^{8}$.

\footnotetext{
${ }^{8}$ A Livraria Francisco Alves foi fundada em 1854 no Rio de Janeiro. A Francisco Alves se constituiu como uma "editora tradicional do segmento de livros didáticos" ainda nos primeiros anos de sua existência, sendo que 1880 o setor dos didáticos ocupava mais de $80 \%$ do catálogo" (Razzini, 2006, p. 4). 
No caso da Editora Melhoramentos, um conglomerado consolidado na área editorial, sobretudo na produção de literatura infanto-juvenil na década de 1970, a baixa representatividade no Plidef/INL ocorreu, provavelmente, em função do fato de que a linha de didáticos havia sido desativada em 1962. Devido a perdas no seguimento foi mantida pela Melhoramentos apenas a produção de alguns títulos didáticos considerados marcos em sua história (Soares, 2010).

É possível especular alguns dos motivos do fato de algumas editoras possuírem uma fatia mais significativa do mercado. A distribuição dos capitais como, por exemplo, recursos econômicos, rede de contatos, posse de direitos autorais, prestígio e reconhecimento de seus autores e obras possibilitam uma maior ou uma menor inserção no campo. Desta forma uma empresa como a Editora do Brasil, que possuía capital de giro suficiente para manter um vasto catálogo e para assegurar a publicação de autores de livros didáticos consagrados, obteve uma presença no campo do Plidef/INL mais significativa do que empresas de porte menor como, por exemplo, a Mor ou a Itatiaia.

No entanto, cabe destacar que a concorrência no mercado editorial também gera um fenômeno nomeado por Thompson (2013) como "eu-também":

A equipe de qualquer editora está sempre de olho no que as concorrentes estão fazendo; esquadrinha as listas de best-sellers e analisa os livros mais bem-sucedidos dessas concorrentes para ver se consegue pistas de como desenvolver seus próprios programas de lançamento. (Thompson, 2013, p. 16)

A publicação de um livro bem sucedido, tanto literário, quanto didático, gera uma série de outros livros semelhantes. As editoras procuram reproduzir o modelo da concorrente que produziu um grande êxito comercial. Esta característica tende a gerar, de certa forma, uma homogeneização das publicações, ao menos até que um novo livro faça sucesso e se torne o modelo a ser seguido.

Em relação aos contratos do programa publicados no DOU foram identificadas onze editoras que fecharam um único acordo com INL por um valor superior a dois milhões de cruzeiros, sendo estas: Abril Cultural, Ao Livro Técnico, Bloch, Caminho Suave, Companhia Editora Nacional, Editora do Brasil, FTD, Ibep, José Olympio, Série Cadernos Didáticos Livros Cadernos e Vigília?

Se considerarmos somente os contratos firmados por um valor acima de cinco milhões de cruzeiros a lista se resume a quatro editoras: Bloch: contrato de Cr\$ 7.215.485,95, com previsão de entrega dos livros em janeiro de 1975, e Cr\$ 13.502.971,65, com previsão de entrega em outubro de 1975; Editora do Brasil: contrato de $\operatorname{Cr} \$ 11.608 .270,00$, com previsão de entrega dos livros em outubro de 1975;

${ }^{9}$ BRASIL. Termos de Contrato. DOU, 10/12/1973, p. 12639-12640; 31/12/1973, p. 13711-13713; 08/ 07/1975, p. 8348-8350; 21/07/1975, p. 9039; 26/08/1975, p. 10928; 15/09/1975, p. 12149; 23/09/1975, p. $12651 ; 24 / 09 / 1975$, p. 12762; 30/09/1975, p. 13077-78; e 12/12/1975, p. 16557. 
FTD: contrato de Cr\$5.205.623,10, com previsão de entrega dos livros em outubro de 1975; e Ibep: contrato de $\mathrm{Cr} \$ 5.339 .676,10^{10}$, com previsão de entrega dos livros em dezembro de 1973; e Cr\$8.498.216,21, com previsão de entrega em outubro $1975^{11}$.

Os dados dos contratos, além de colaborarem para a percepção do estabelecimento de um quase monopólio por um número reduzido de editoras do campo do Plidef/INL, também permitiram a criação de indicadores para balizar as informações sobre os números de títulos coeditados por editora. A Editora Tabajara, por exemplo, editou 53 títulos pelo Plidef/INL, contudo, não foi localizada nenhuma referência que indicasse o fechamento de um único contrato por um valor igual ou superior a um milhão de cruzeiros. Por outro lado, a Editora Caminho Suave, que coeditou apenas oito títulos, recebeu do INL um montante maior, cerca de dois milhões de cruzeiros.

Isso significa dizer que mesmo com um catálogo reduzido, uma editora poderia obter o fechamento de um contrato de coedição por um alto montante, inclusive superior ao montante recebido por outras editoras com um maior número de títulos. No entanto, a comparação entre a Editora Tabajara e a Editora Caminho Suave parece ser a exceção e não a regra. De forma geral, as editoras com um catálogo mais amplo possuíam uma maior quantidade de títulos coeditados e, consequentemente, fechavam contratos com valores mais altos.

Alguns dos contratos publicados entre o Instituto e as editoras no DOU não nomeiam de forma direta a coedição como sendo integrante do Plidef/INL, nem apresentam os títulos das obras ou a série escolar destinada. Apesar disso estes dados foram considerados parcialmente na análise por três motivos: os contratos de outros Programas de livro didático desenvolvidos pelo INL apresentavam a identificação, por exemplo, do Programa do Livro Didático para o Ensino Supletivo - Plidesu; algumas das editoras que firmaram convênio por esses tipos de contratos produziam exclusivamente para o ensino de $1^{\circ} \mathrm{Grau}$, como a Caminho Suave; as testemunhas que assinaram os contratos estavam, em sua maioria, associadas ao Plidef/INL .

Sobre os contratos sem identificação do Plidef/INL destacam-se aqueles firmados com Editora Ática. No ano 1975 foram localizados dois contratos do INL com a Editora Ática por um montante de Cr\$1.405.815,66 (Brasil, termos de contrato, DOU, 04/07/1975, p. 8236; 8 jul., 1975, p. 8350). Contudo, não foi encontrado nos catálogos do Instituto publicações da Ática para o ensino de $1^{\circ}$ Grau. Algumas hipóteses podem ser consideradas na explicação deste fenômeno, ainda que de forma restrita: os livros coeditados não foram inclusos na lista dos catálogos do INL; o contrato não foi cumprido por parte da editora e os livros não foram entregues no prazo; os livros coeditados não faziam parte do Plidef. Esta mesma circunstância de publicação de contrato no DOU, mas ausência de títulos nos catálogos ocorreu em relação a Editora Vozes e a Lê Editora (Brasil, termos de contrato, DOU, 4 jul., 1975, p. 8236-8237; 12 dez., 1975, p. 16557).

As editoras identificadas como integrantes do Plidef/INL têm suas matrizes em quatro cidades: São Paulo: Abril Cultural, Caminho Suave, Companhia Editora Nacional, Edart, Editora do Brasil, Formar, FTD, Ibep, J. Ozon, Liceu, Lisa, Melhoramentos, Mestre

\footnotetext{
${ }^{10}$ No ano de 1973 foram publicados dois contratos entre o INL e a lbep pelo montante de Cr\$5.339.676,10. No entanto, entendeu-se que houve um erro por parte do Instituto na divulgação dos contratos, sendo considerado apenas um dos valores.

${ }^{11}$ BRASIL. Termos de contrato. DOU, 10/12/1973, p. 12639-12640; 08/07/1975, p. 8349; 26/08/1975, p. 10928; 15/09/1975, p. 12149; 23/09/1975, p. 12651; e 30/09/1975, p. 13077-78. 
Jou, Mor e Saraiva; Rio de Janeiro: Agir, Alfa Sigma, Ao Livro Técnico, Bloch, Conquista, Edild, Exped-Expansão, Francisco Alves, Gráfica Editora Primor, José Olympio, Minerva, Record e Série Cadernos Didáticos; Belo Horizonte: B. Alvares; Eddal; Itatiaia; Lemi; Vega e Vigília; e Porto Alegre: Globo e Tabajara.

A maior concentração de um número expressivo de editoras em São Paulo confirma, tendo em consideração o campo do Plidef/INL, o seu título de "cidade dos livros didáticos brasileiros" (Razzini, 2010, p. 120). É preciso destacar, contudo, que as editoras também imprimiam livros didáticos em outras cidades que não a sua matriz como, por exemplo, a Editora do Brasil com a coleção Estórias Bonitas feita em Belo Horizonte e integrante da Coleção Didática de Minas Gerais, e com o livro Estudos Sociais: família, escola, comunidade: ensino de $1^{\circ} \mathrm{grau}$, produzido em Salvador.

\section{Plidef/INL e estratégias editorais}

Os pretendentes de um campo, os challengers, "estão condenados a 'fazer o jogo', a assumir os riscos" frente aos detentores de um maior acúmulo de capital, seja esse de natureza econômica, cultural ou social. Contudo, "da luta interna não podem senão sair revoluções parciais, capazes de destruir a hierarquia mas não o próprio jogo" ((Bourdieu, 2003, p. 208).

Ao discutir as competições e as rivalidades no processo de difusão e de circulação dos impressos didáticos, Cardoso (2011) considera que "a história dos livros está repleta de estratégias dos autores e dos editores para difundir as obras: exposições, cartas, concurso e doações são ardis comuns a esses segmentos com o intuito de ver uma obra divulgada, lida, adotada, utilizada" (p. 206).

Uma das ações era o envio de cartas para as escolas em conjunto com um ou mais livros didáticos:

Porto Alegre, 21 de fevereiro de 1973.

Ao

Col. Municipal Pelotense

PELOTAS = RS

Prezado diretor:

Para apreciação de V.Sa., estamos enviando em anexo, as obras didáticas abaixo relacionadas:

1 Col. ANTONIO LAGES FRANÇA $=$ PORTUGUES $1^{\circ} 2^{\circ} 3^{\circ} 4^{\circ} \mathrm{C} / \mathrm{MAN}$. DO MESTRE

1. CoI. LADMO VALUCE $=$ HISTORIA DO BRASIL E GERAL

1. EX. OTTO COSTA = EDUCAÇÃO MORAL E CIVICA

EXEMPLAR DA REVISTA EBSA No297

Apreciaremos muitíssimo contar com sua preferência na indicação das suas classes.

A carta da Editora do Brasil, em um tom cordial, foi enviada ao diretor do Colégio Municipal Pelotense ${ }^{12}$ junto com uma coleção de livros de Português, um livro de História, um livro de Moral e Cívica e uma revista para que fossem conhecidos e apreciados pelos

${ }^{12}$ O Colégio Municipal Pelotense foi criado em 1902 na cidade de Pelotas, Rio Grande do Sul. O Colégio organiza e preserva diferentes fontes históricas em um museu escolar. Para saber mais, ver AMARAL, Giana Lange do. O acervo documental do museu do Colégio Municipal Pelotense e sua importância para a história da educação. Hist. Educ. (Online), Porto Alegre, v. 19, n. 47, 2015, p. 327-330.

p. $219-241$ 
professores para possível indicação. Ao final da carta é salientado que "apreciaremos muitíssimo contar com a sua preferência na indicação das suas classes". Outro aspecto que merece de destaque nessa carta é a apresentação da matriz e das filiais da Editora do Brasil: São Paulo, Manaus, Belém, São Luiz, Teresinha, Fortaleza, João Pessoa, Natal, Recife, Maceió, Salvador, Vitória, Rio de Janeiro, Goiânia, Brasília, Campo Grande, Ribeirão Preto, Santo André, Curitiba, Florianópolis e Porto Alegre, o que permite observar a extensa rede de entrepostos da editora. A correspondência foi assinada por Jair M. Bauitor ${ }^{13}$.

Outra ação das editoras para garantir a indicação do livro, e posterior impressão e compra pelo Programa era a distribuição de exemplares de forma gratuita, que pode ser observada nas imagens 3, 4 e 5.

Figura 3 -

Carimbo na folha de rosto do livro Cartilha Arco-Íris.

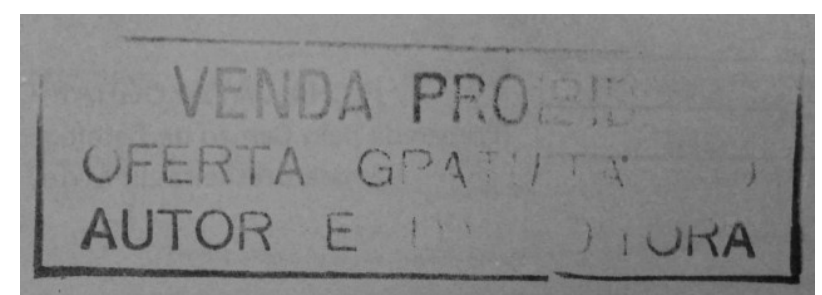

Fonte: Cartilha Arco-Íris. São Paulo: Saraiva, 1976. Acervo Hisales/FaE/UFPel ${ }^{14}$.

Figura 4 -

Carimbo na folha de rosto do livro no Reino da Alegria.

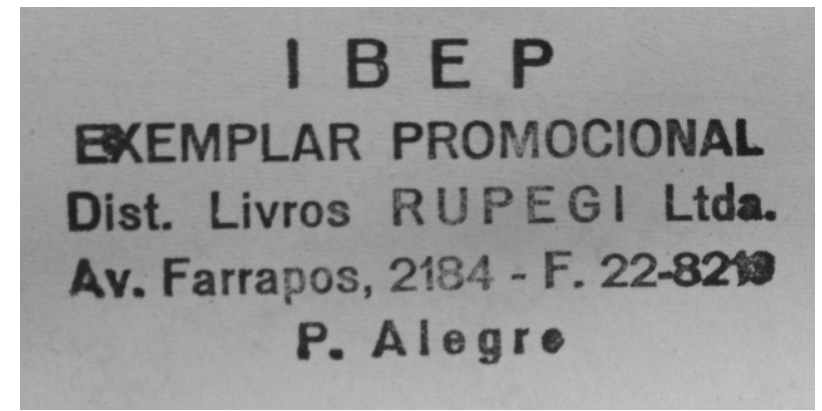

Fonte: No Reino da Alegria: cartilha. São Paulo: IBEP, s/d. Acervo Hisales/FaE/UFPel).

\footnotetext{
${ }^{13}$ Não foi possível identificar nenhuma informação sobre Jair M. Bauitor. Talvez tratava-se de algum funcionário responsável pelo setor de propaganda ou de distribuição da Editora do Brasil.

${ }^{14} \mathrm{O}$ Grupo de Pesquisa História da Alfabetização, Leitura, Escrita e dos Livros Escolares - Hisales -, da Universidade Federal de Pelotas, mantém acervos de cartilhas e livros de alfabetização em língua nacional e estrangeira, livros didáticos produzidos no Rio Grande do Sul, cadernos de crianças em fase de alfabetização, cadernos de planejamento de professoras alfabetizadoras, e materiais didático pedagógicos. Sobre o trabalho do Hisales, indica-se: PERES, Eliane. A produção sobre história da alfabetização no Rio Grande do Sul: as contribuições do grupo de pesquisa Hisales (FaE/UFPel). In: MORTATTI, Maria do Rosário Longo (org.). A alfabetização no Brasil: uma história da sua história. São Paulo: Cultura Acadêmica; Marília: Oficina Universitária, 2011, p. 243-264.
} 
Figura 5 -

Carimbo na folha de rosto do livro História do Brasil, $1^{\circ} \mathrm{Grau}$, da $5^{\mathrm{a}}$ à $8^{\mathrm{a}}$ série.

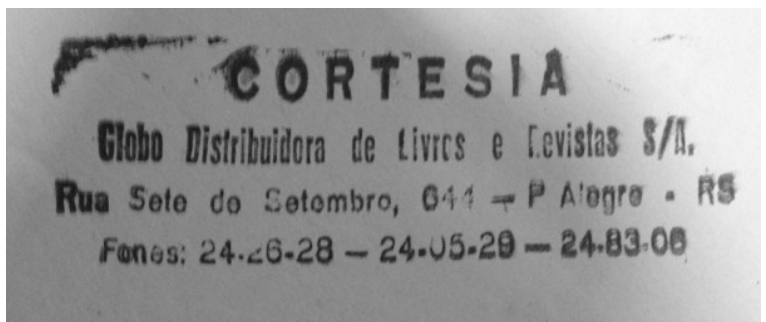

Fonte: História do Brasil, $1^{\circ} \mathrm{Grau}$, da $5^{\mathrm{a}}$ à $8^{\mathrm{a}}$ série. São Paulo: Lisa, s/d. Acervo Museu do Colégio Municipal Pelotense.

Na figura 3 o carimbo adverte "VENDA PROIBIDA" e caracteriza o livro como uma oferta gratuita do autor, neste caso Idalina Ladeira Ferreira, e da Editora Saraiva. Na figura 4 o carimbo indica "EXEMPLAR PROMOCIONAL" e associa a Editora Ibep a Distribuidora de Livros Rupegi de Porto Alegre. Por fim, na figura 5 o carimbo assinala apenas a "CORTESIA" da Globo Distribuidora de Livros e Revista, sem mencionar a participação da Editora Lisa. As três figuras exemplificam ações diferentes de distribuição e contato com os professores que garantia o alcance do livro entre aqueles que poderiam ter alguma ingerência sobre as indicações. Assim, é preciso levar em consideração que "um manual é, ao mesmo tempo, a oferta pedagógica de um autor e a oferta comercial de um editor", como afirma Chartier (2007, p. 70).

Esta prática de ofertar livros aos professores tinha, na maior parte dos casos, como base $5 \%$ da tiragem da edição, podendo inclusive ultrapassar os $10 \%$ no lançamento de novos títulos (Jornal do Brasil, 27 fev., 1971, p. 1). As editoras chegavam à anunciar, nos classificados, a busca por profissionais qualificados para a distribuição, como, por exemplo, no seguinte reclame: "Editora de âmbito Nacional, está selecionando pessoas qualificadas para apresentação de suas obras na Grande Rio e no Est. do Rio de Janeiro. Preferência Elementos motorizados. Remuneração condizente, mais prêmios" (Jornal do Brasil, 20 maio, 1973, p. 12).

Sobre a prática de divulgação dos livros didáticos Luis Roberto Malta, gerente editorial da Saraiva, explicou que os professores recebiam os exemplares direto na escola ou em casa e que a atividade de representante editorial diminuía em importância todos os anos, sendo substituída pelo uso dos correios (Folha de São Paulo, 7 out., 1973, p. 20). Contudo, a afirmação da substituição do contato pessoal dos representantes pelo serviço dos correios não possui outro indício plausível observado nos dados da pesquisa. Ao que parece as duas estratégias eram utilizadas em conjunto.

Ainda sobre a distribuição gratuita de exemplares José Otávio Bertaso comentou a atuação do Departamento de Divulgação da Editora Globo que enviou "um jogo completo da série Era uma Vez, para que fosse apreciada e eventualmente adotada" para uma relação de mil escolas do interior do Rio Grande do Sul fornecida pela SEC do Estado (Bertaso, 1993, p. 229). Na citação de Bertaso percebe-se a conexão entre as atividades da Editora Globo e o fornecimento de informações por parte da SEC do Rio Grande do Sul. 
Outra possibilidade de divulgação dos materiais didáticos era a publicação de comentários sobre o lançamento dos livros didáticos na imprensa, conforme visualizado nas citações a seguir.

Lançamento de livro didático de autoria de Enoi Renee Navarro Swain, pela FTD:

ENOI Renee Navarro Swain, gente nossa, e das boas, acaba de lançar um livro didático para o segundo grau primário. Enoi é conhecida professora e autora de livros didáticos. O lançamento é da editora FTD, de São Paulo (tinha de ser de outro Estado). E' assim que exportamos os nosso talentos. O nosso mar está cheio de peixes e os pescadores andam por ai, levando o melhor da tarrafada (Diário do Paraná, 5 mar., 1972, p. 5)

Lançamento do livro didático Estudos Sociais e Ciências pela Editora lara Ltda.:

A Editora lara Ltda. hoje de propriedade do escritor conterrâneo J. Lucídio Rondon, está lançando agora o livro didático Estudos Sociais e Ciências, orientado em termos de Mato Grosso. Segundo declarações do editor, a mencionada obra "foi elaborada com muito amor e carinho, de acordo com a orientação programática, atendendo a lei 5.692 e resolução do Conselho Federal de Educação, com ilustrações e conteúdo relacionados com ambiente para despertar nas crianças interesse e entusiasmo pela nossa terra e nossas coisas". E finaliza o escritor J; Lucídio Rondon: "Está havendo muita boa-vontade de nossa parte. Agora necessitamos de apoio das autoridades e dos professores para que possamos dar continuidade, publicando outras obras sobre o nosso Estado. (O Estado de Mato Grosso, 18 abr., 1974, p. 2)

Em ambos os comentários sobre os lançamentos de livros didáticos percebe-se a utilização de uma linguagem com caráter afetivo, ao descrever a autora "gente nossa, e das boas" ou a obra "elaborada com muito amor e carinho". No primeiro comentário o foco é a autora e um aspecto interessante é a expressão de um certo ressentimento por parte do jornal do Paraná sobre a publicação de uma autora paranaense por uma editora de outro Estado. No segundo comentário o foco é a obra, um livro didático "orientado em termos de Mato Grosso", sendo ainda ressaltado que a Editora lara precisaria do apoio das autoridades e professores para "dar continuidade, publicando outras obras sobre o nosso Estado".

Também eram realizadas mostras de livros didáticos, com a exposição de obras consagradas ou pré-lançamentos. Doze editoras participaram da I Mostra do Livro Didático, em Petrópolis, RJ. Durante a mostra foram distribuídos a professores "exemplares em forma de provas tipográficas dos seus livros a editar em janeiro de 1972 e os resultados dos manuais adotados em caráter experimental, este ano, por alguns educandários cariocas" (Jornal do Brasil, 19 dez., 1971, p. 23). Assim, pode-se perceber que as estratégias de propaganda dos livros eram muitas e variadas, com ações que visavam alcançar os sujeitos capazes de impulsionador as vendas das obras didáticas.

Outra forma de agir no sentido de divulgar os livros que as editoras usavam era a publicação de propagandas em veículos de comunicação, conforme exemplificado pela figura 6. 
Figura 6 -

Propaganda da Editora Lisa.

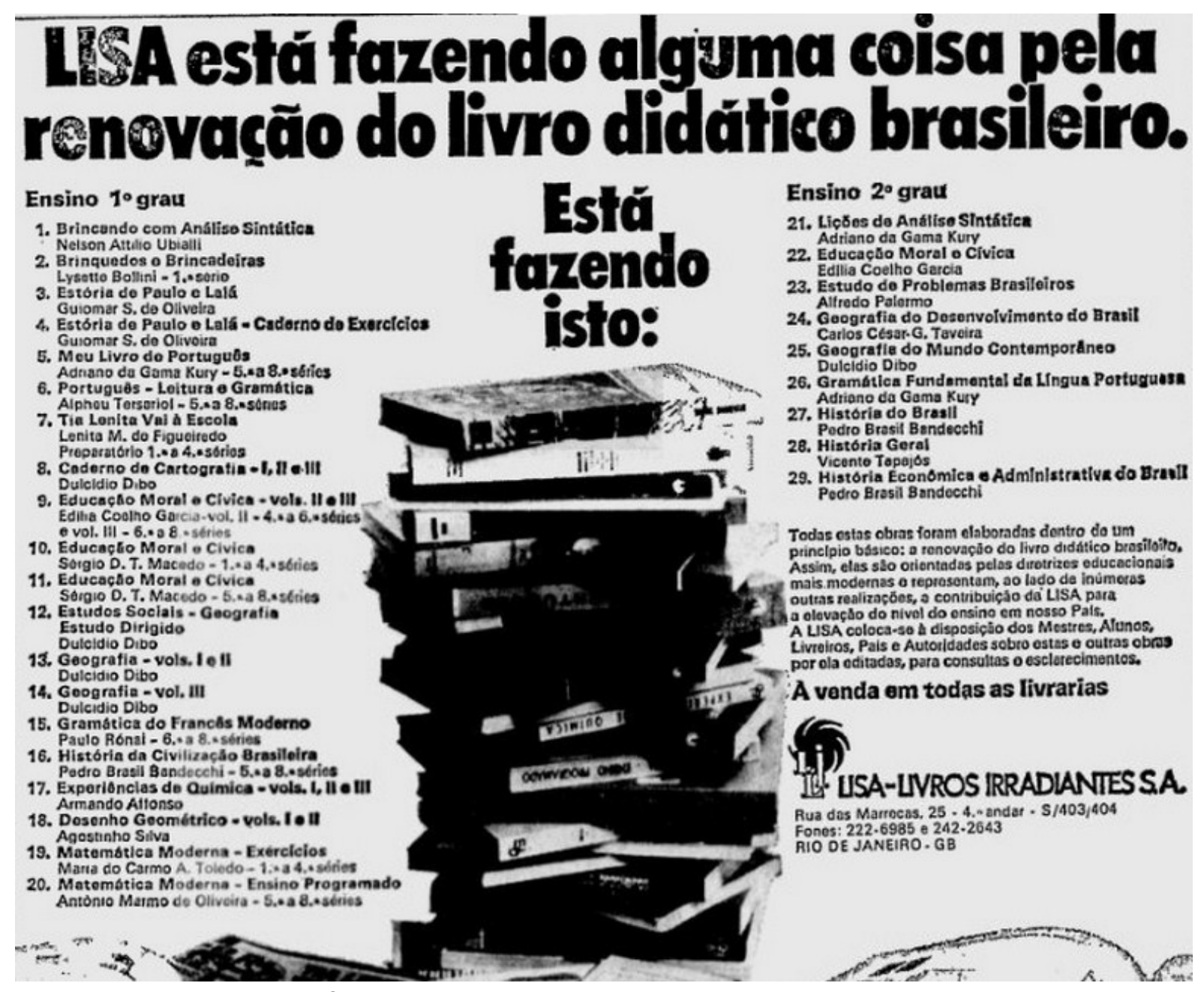

Fonte: Jornal do Brasil, 11 fev., 1973, p. 18.

Como se pode ver a ação de marketing da Editora Lisa usava como argumento a contribuição que oferecia para "a elevação do nível do ensino em nosso País" ao publicar livros didáticos para o ensino de $1^{\circ}$ e $2^{\circ}$ Graus dos diferentes componentes curriculares. As obras teriam sido "elaboradas dentro de um princípio básico: a renovação do livro didático brasileiro" e estariam "orientadas pelas diretrizes educacionais mais modernas" (Jornal do Brasil, 11 fev., 1973, p. 18). Observa-se, na imagem acima, o reforço na difusão do discurso do novo e do moderno na educação por parte da editora.

Mais uma estratégia de divulgação utilizada pela Editora Série Cadernos Didáticos era a realização de concursos:

Os professores de $1^{\circ}$ Grau das redes oficiais e particular da Guanabara poderão ganhar uma viagem a Europa, através do concurso lançado pela Editora Série Cadernos Didáticos. A promoção tem como objetivo chamar atenção do professorado para problemas referentes ao Livro Didático e ao Turismo. $\mathrm{O}$ melhor trabalho sobre o livro didático receberá uma viagem à Europa, enquanto que o melhor trabalho sobre turismo terá como prêmio uma viagem pelo Brasil. O regulamento está sendo distribuído a todos os estabelecimentos de ensino da Guanabara (Diário de Notícias, 23 mai., 1973, p. 5) 
Como se observa, o investimento das editoras na divulgação de seus livros era grande. O concurso realizado pela Editora Série Cadernos Didáticos para os professores prometia uma viagem a Europa para o melhor trabalho sobre os problemas referentes ao livro didático. A opção pela realização de concursos era vantajosa para as editoras na medida em que impulsionava a publicação de artigos em diferentes veículos de comunicação e chamava a atenção dos docentes para a produção de livros didáticos de determinada empresa. Possivelmente se uma editora promovia um concurso cujo prêmio era uma viajem à Europa, era porque os lucros na venda de um livro, caso fosse coeditado, eram bastante vantajosos.

Neste exemplo, cabe salientar a diferença entre marketing e publicidade. Ao discutir o mercado editorial anglo-saxão Thompson (2013, p. 27) afirma que ambos "tem o mesmo objetivo - ou seja, chamar a atenção dos consumidores/leitores para os livros e persuadilos a comprá-los; a única diferença real é que a editora paga pelo marketing, enquanto que a publicidade, quando se consegue, é grátis". Além da realização de concursos outra estratégia que gerava publicidade gratuita para as editoras era a realização de encontros e cursos.

As editoras promoviam esses encontros e cursos de formação para os professores, ocupando um espaço relativamente carente de esforços do poder público no período. Em 1973, por exemplo, foi firmado um convênio entre o governo fluminense e a Divisão Educação da Abril Cultural para a realização do Curso de Atualização do Livro Didático, elaborado por Antônio Soares Amora (Veja, 5 dez., 1973), demonstrado na imagem abaixo.

Figura 7 -

Material do curso de atualização do livro didático.

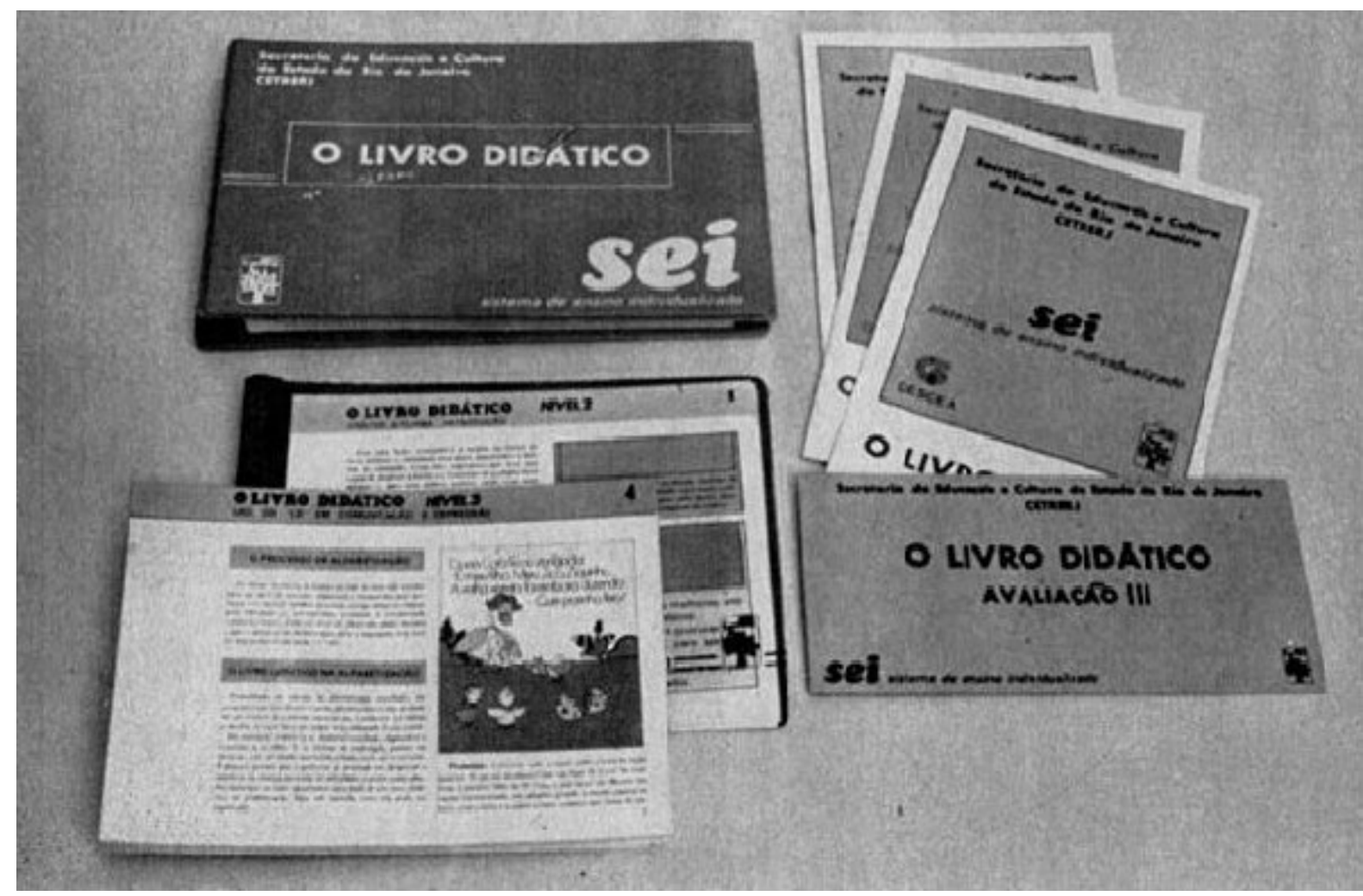

Fonte: Veja, 5 dez., 1973, p. 74 
O curso sobre livro didático era organizado em fichas impressas que eram enviadas pelo correio. Como justificativa para o curso Lucy Vereza, professora e diretora geral Centro de Treinamento de Professores do Estado do Rio de Janeiro - Cetrej -, afirmou: "é difícil acreditar, [...] mas raramente professores sabem explorar as potencialidades do livro" (Veja, 5 dez., 1973, p. 74). A concepção do despreparo dos educadores perpassa também a questão dos livros didáticos adaptados aos currículos estaduais. Nesse sentido, Jiro Takahashi, editor da Ática, comenta que

se você lançar um livro bem feito, de agrado dos professores e colocar lá no frontispício: 'de acordo com os guia curriculares do Espírito Santo' todos os professores de lá, se não entenderam bem a proposta curricular do estado, vão acabar adotando aquele programa, e não o guia. O livro passa a ser o próprio guia (Oliveira, Guimarães; Bomény, 1984, p. 73)

Pela citação de Jiro Takahashi é possível apreender que as editoras concluíram que uma parcela significativa dos professores não entendia a proposta curricular estadual e que bastava o livro didático apresentar a frase "de acordo com os guias curriculares" para ser adotado. Nesta lógica, os programas de ensino eram abandonados e os próprios livros tornavam-se os definidores do conteúdo e da metodologia empregados, ou seja, do próprio currículo escolar. As editoras fizeram uma aposta significativa nessa possibilidade.

\section{Desentendimentos, pressões editorais e o término do Plidef/INL}

Em 1976 a gestão do Plidef foi repassada do INL para a Fename. O primeiro indício encontrado sobre os possíveis motivos que teriam levado essa transferência relaciona-se com a produção do livro integrado. O livro integrado era uma proposta do INL para reduzir a quantidade de livros utilizados ao longo da vida escolar. A integração poderia ocorrer tanto verticalmente, por componente curricular, quanto horizontalmente, por série escolar. A citação a seguir, apesar de longa, colabora para esclarecer este episódio:

Uma ideia para reduzir ainda mais o custo dos livros escolares, apresentada no VI Encontro Nacional os Coordenadores do Livro Didático (Brasília, 1975), foi a do livro integrado: um só texto que cobrisse todo o material para as quatro primeiras séries, a ser produzido com o apoio do Ministério da Educação. Uma vez que se previa uma edição de dez milhões de exemplares, argumentava-se que as economias de escala seriam maximizadas. Embora com isso não se visasse especificamente a produzir a uniformidade, dificilmente se teria podido evitar a criação de uma concentração maior do mercado. Todavia, os órgãos de classe dos editores acabaram demonstrando inequivocamente que - além dos riscos educacionais e ideológicos envolvidos em sua possível transformação, na prática, em livro único (dado o envolvimento do Ministério da Educação) - o resultado não seria econômico. Ao contrário. Ao fato de a economia de escala ser desprezível em faixas de milhões de exemplares somava-se outro, dizia-se, mais grave e que não havia sido levado em conta nos estudos de sua viabilidade: a elevadíssima evasão escolar no Brasil tornaria seu custo, do ponto de vista prático, muito mais elevado que o das edições comerciais existentes no mercado. De qualquer modo, parece que o projeto acabou sendo fulminado pelo próprio MEC quando se soube que ele teria sido concebido para beneficiar uma única editora, sem expressão, a qual, segundo algumas fontes, fora autora do projeto e já possuía tudo pronto para impressão. (Hallewell, 1985, p. 469) 
Observa-se, na citação, o anúncio da publicação do livro integrado no VI Encontro Nacional os Coordenadores do Livro Didático do Plidef/INL, realizado em Brasília no ano de 1975. O principal argumento para o livro integrado era a redução de custos. O excerto acima também indica a mobilização dos órgãos dos editores contrários ao livro integrado. Por fim, o autor afirma a dissolução da proposta tendo em vista o beneficiamento de uma única editora "sem expressão", que já possuiria "tudo pronto para impressão" (Hallewell, 1985, p. 471).

O anúncio de uma coleção de livros didáticos integrados no VI Encontro Nacional dos Coordenadores do Programa do Livro Didático também foi citado pelo Jornal do Brasil:

O Ministro da Educação abrirá hoje, às 10 horas, no Itamarati, o VI Encontro Nacional dos Coordenadores do Programa do Livro Didático, organizado pelo Instituto Nacional do Livro, cujo principal destaque é a coleção Proler, aprovada pelo MEC, que servirá para quatro séries, sem modificações de ano para ano. A criação do Banco do Livro, nas escolas beneficiadas pelo INL, será um dos temas examinados durante o Encontro, cuja tarefa básica é prolongar a vida útil do livro; facilitar o acesso ao livro; ampliar o acervo bibliográfico das escolas; desenvolver o hábito da leitura e o amor ao livro; e estimular o cuidado com o patrimônio comum. (Jornal do Brasil, 14 abr., p. 14)

A coleção Proler parece ter sido o principal destaque do $6^{\circ}$ encontro, quando se anunciariam também medidas para a efetivação do Banco do Livro. Uma série de oito reportagens do jornal Diário de Notícias, publicadas entre novembro e dezembro de 1975, também contribuiu para a compreensão da transformação da coleção Proler, que num primeiro momento era percebida como solução para a concepção de livro didático pelo MEC, para logo em seguida se tornar um incômodo para o Ministério.

Nas primeiras reportagens do Diário de Notícias a coleção Proler foi apresentada como "a grande revolução em 500 anos de livros didáticos". Os livros incluiriam todo o conteúdo dos quatro primeiros anos do ensino de $1^{\circ} \mathrm{Grau}$ em um volume por componente curricular: Comunicação e Expressão, Matemática, Estudos Sociais e Ciências Naturais. O material seria organizado em livros textos geradores de caráter durável, os livros de atividades de caráter consumível e o livro do professor (Diário de Notícias, 8 nov., 1975, p. 6). Sobre o processo de avaliação e fechamento do contrato com o INL, Mauro Magalhães ${ }^{15}$ comentou que

certo de que todos nós devemos utilizar toda a nossa capacidade de criatividade, de execução e de trabalho em favor do desenvolvimento nacional. $E$ certo, também, de que, educação é investimento e não despesa. E que precisamos nacionalizar nosso ensino fundamental, foi que trabalhando dia e noite reunindo os melhores autores do Brasil partimos para a realização do Livro Integrado, que apresentado ao Instituto Nacional do Livro e ao Departamento de Ensino Fundamental do Ministério da Educação e Cultura, depois de profundamente analisado e julgado pelos órgãos competentes, foi levado pelo Diretor do I.N.L, Dr. Herberto Salles, pela Diretora do D.E.F., Prof ${ }^{a}$ Anna Bernardes, pela então Coordenadora

\footnotetext{
${ }^{15}$ Não foi possível identificar nenhuma informação sobre Mauro Magalhães, no entanto, pelo conteúdo das reportagens publicadas no Diário de Notícias é possível supor que Magalhães estivesse, de alguma forma, envolvido na publicação da coleção Proler. 
do Livro Didático Prof ${ }^{a}$ Cosete Ramos ao Ministro Ney Braga, que entusiasmado, na nossa presença, autorizou àquelas autoridades a executar um projeto especial para aplicação do mesmo na Zona Rural no ano letivo de 1976. Posteriormente, recebemos do I.N.L. o ofício da aprovação de uma verba de cinco milhões de cruzeiros para a execução dos livros e lá estivemos reunidos com os diretores de todos os Departamentos e presidido pelo Dr. Herberto Salles, quando ficou acertado o número de livros a serem produzidos e o prazo para a entrega. (Diário de Notícias, 8 nov. 1975, p. 6)

A partir da citação acima se percebe que coleção Proler teria seguido a estrutura de funcionamento do Plidef/INL, ao menos nos dois primeiros passos: encaminhamento dos livros pelas editoras e avaliação pelo Departamento de Ensino Fundamental do MEC. Contudo, o entusiasmo do então ministro da Educação, Ney Braga, teria levado à organização de um projeto especial para as escolas rurais, aprovando uma verba de cinco milhões de cruzeiros para a produção dos materiais. Cabe destacar que, apesar de cinco milhões de cruzeiros ser um montante significativo no período, outras editoras receberam um valor superior no mesmo ano em convênio com o Plidef/INL, conforme mencionado anteriormente.

Apesar de ter sido enviado um ofício comprovando o compromisso do MEC com a publicação da Coleção Proler, o Instituto voltou atrás em sua decisão e os materiais não foram coeditados. Os idealizadores do projeto culparam os "abutres da educação" que "vivem das modificações anuais dos livros didáticos consumíveis" pelo fracasso do convênio com o INL (Diário de Notícias, 12 dez., 1975, p. 6). A editora, nunca nomeada pela série de reportagens, teria tido um prejuízo superior aos $\mathrm{Cr} \$ 2.000 .000,00 \mathrm{com} o$ retrocesso da posição do Instituto (Diário de Notícias, 19 dez, 1975, p. 6).

A transferência oficial do Plidef, junto com os outros programas de coedição de livros didáticos para a Fename, ocorreu em fevereiro de 1976 com a publicação do decreto n. 77.107 (DOU, 5 fev., 1976, p. 1681). Contudo, a imprensa já noticiava a mudança na coordenação do Programa por decreto presidencial em dezembro de 1975, conforme visualizado na citação abaixo:

A partir de ontem o livro didático é de competência exclusiva da Fundação do Material Escolar [...]. Ao anunciar a medida, Ney Braga esclareceu que o Instituto Nacional do Livro que vinha se ocupando do assunto e movimentando tais verbas terá sua competência limitada à área da cultura [...]. Na exposição de motivos, Ney lembra que a despeito do êxito que o INL vinha obtendo no setor, compete realmente à Fename, dentro das atribuições que o decreto de sua criação estabeleceu, a finalidades de definir as diretrizes quanto à produção de material didático, inclusive livros. (Diário de Notícias, 24 dez., 1975, p. 6)

Para Cosette Ramos, assessora da Coordenação do Livro Didático do INL, "o anão teve que absorver o gigante" (Oliveira; Guimarães; Bomény, 1984, p. 63). A transferência do Programa para a coordenação da Fename, possivelmente motivada pela pressão das editoras contrárias à coedição do livro didático integrado, e o desconforto institucional causado em relação à quebra de convênio com a Coleção Proler, gerou uma "revolução parcial no jogo" (Bourdieu, 2003). No entanto, independentemente do órgão público responsável pelo Programa, as regras do jogo e o lugar do livro didático nas políticas públicas federais foi preservado. 
Cabe ainda destacar que o Instituto teve seus recursos diminuídos sensivelmente após a transferência do Programa do Livro Didático para Fename. O INL também foi afetado com a queda no interesse por parte dos municípios na manutenção de bibliotecas ou salas de leituras, contrapartida exigida para o recebimento de livros didáticos e que perdeu o sentido após a mudança na coordenação do Plidef. O INL não coeditou mais livros didáticos, contudo, manteve a coedição de livros literários até 1986, sendo integrado a Fundação Nacional Pró-Leitura em 1987. O encerramento de suas atividades ocorreu em 1990.

\section{Considerações finais}

O Plidef/INL coeditou 927 títulos por meio de convênio com 36 editoras no período de 1971-1976. Entretanto, somente nove editoras - Ao Livro Técnico, Ibep, Editora do Brasil, Abril Cultural, Companhia Editora Nacional, FTD, Tabajara, Bloch e Vigília representam a produção de mais de $70 \%$ do número de títulos coeditados, o que demonstra a concentração de investimentos públicos em um pequeno número de empresas privadas. Uma parte destas editoras continuam com alta representatividade no programa federal atual de subsídios de livros didáticos ${ }^{16}$.

A partir destes dados de compra de livro didático pelo governo federal observou-se o estreitamento do estabelecimento de parcerias entre o setor público e o setor privado, nomeadamente da relação de dependência das editoras em relação às políticas governamentais. O mercado escolar, subsidiado pelo governo federal, consolidou-se no período estudado como um dos principais meios de obtenção de capital econômico por parte das editoras.

Como estratégias de difusão de seus impressos as editoras distribuíam exemplares gratuitos em escolas, publicavam propagandas dos catálogos e comentários sobre os lançamentos dos livros na imprensa, realizavam concursos, promoviam encontros e cursos de formação para os professores. Assim, quanto maior o volume de capital econômico que as editoras tivessem à sua disposição na divulgação dos seus materiais, maior a possibilidade de retorno. Esta característica favorecia a conservação da posição de algumas editoras frente às recém criadas e com pouco tempo de atuação no campo.

Sobre o encerramento do Plidef/INL, apesar de não haver um indício que confirme a ligação direta entre a substituição do INL pela Fename e a confusão gerada em torno da Coleção Proler, é plausível imaginar que a pressão das editoras contrárias ao livro integrado e o mal estar causado pela série de reportagens sobre a coleção teriam deixado o Instituto em uma posição delicada. Talvez naquele momento a opção de repassar os programas do livro didático para a Fename tenha sido percebida como positiva, pois pouparia esforços e permitira ao INL concentrar suas ações no livro literário.

Sobre a transferência ainda cabe destacar que "as revoluções parciais de que os campos são continuamente lugar não põem em questão os fundamentos do próprio jogo, a sua axiomática fundamental, o alicerce de crenças últimas sobre as quais assenta todo o jogo" (Bourdieu, 2003, p. 122). Assim, apesar da mudança no Plidef, o lugar do livro

\footnotetext{
${ }^{16}$ Sobre a participação das editoras no PNLD indica-se CASSIANO, Célia Cristina de Figueiredo. O mercado do livro didático no Brasil: da criação do Programa Nacional do Livro Didático (PNLD) à entrada do capital internacional espanhol (1985-2007). São Paulo: PUCSP, 2007. 234f. Tese (doutorado em Educação), Pontifícia Universidade Católica de São Paulo.

\begin{tabular}{|l|l|l|l|l|l|}
\hline Hist. Educ. (Online) & Porto Alegre & v. 20 & n. 50 & Set./dez., 2016 p. $219-241$
\end{tabular}
} 
didático como política pública na educação brasileira continuou sólido e o investimento maciço por parte do governo federal na compra e distribuição desses materiais se mantém até os dias atuais.

\section{Referências}

A LISA está fazendo alguma coisa pela renovação do livro didático brasileiro. Jornal do Brasil, 11 fev. $1973,1^{\circ}$ caderno, p. 18.

ALMEIDA, Doracy de Paulo Falleiros de. No Reino da Alegria: cartilha. São Paulo: Ibep, s/d.

AVISO. Ministério da Educação e Cultura. Instituto Nacional do Livro. Jornal do Brasil, 28 fev. $1974,1^{\circ}$ caderno, p. 14.

BANDECCHI, Brasil. História do Brasil. $1^{\circ} \mathrm{Grau}$, da $5^{\mathrm{a}}$ à $8^{\mathrm{a}}$ série. São Paulo: Lisa, s/d.

BERTASO, José Otávio. O. A Globo da Rua da Praia. São Paulo: Globo, 1993.

BOURDIEU, Pierre. O poder simbólico. Lisboa: Difel; Rio de Janeiro: Bertrand, 1989.

BOURDIEU, Pierre. Sociologia. São Paulo: Ática, 1994.

BOURDIEU, Pierre. Sobre a televisão. Rio de Janeiro: Zahar, 1997.

BOURDIEU, Pierre. Questões de sociologia. Lisboa: Fim de Século, 2003.

BRASIL. Decreto n. 68.728/1971. Provê sobre a política do livro técnico e do livro didático e dá outras providências. DOU, 11/06/1971, p. 4456-4457. Disponível em <http://www2.camara.gov.br/legin/fed/decret/1970-1979/decreto-68728-9-junho-1971410492-publicacaooriginal-1-pe.html>. Acesso em 15 out. 2012.

BRASIL. Decreto n. 77.107/1976. Dispõe sobre a edição e distribuição de livros textos e dá outras providências. DOU, 05/02/1976, p. 1681. Disponível em <http://www2.camara.leg.br/legin/fed/decret/1970-1979/decreto-77107-4-fevereiro-1976425615-publicacaooriginal-1-pe.html>. Acesso em 15 out. 2012.

BRASIL. Termos de contrato. DOU, 10/12/1973, p. 12639-12640; 31/12/1973, p. 13711 13713; 08/07/1975, p. 8348-8350; 21/07/1975, p. 9039; 26/08/1975, p. 10928; 15/09/1975, p. 12149 ; 23/09/1975, p. 12651 ; 24/09/1975, p. $12762 ; 30 / 09 / 1975$, p. 13077-78; e 12/12/1975, p. 16557. Disponível em: <http://www.jusbrasil.com.br/>. Acesso em 17 out. 2014.

CARDOSO, Cancionila Janzkovski. Cartilha Ada e Edu: produção, difusão e circulação (1977-1985). Cuiabá: UFMT, 2011.

CHARTIER, Anne-Marie. Práticas de leitura e escrita. Belo Horizonte: Autêntica, 2007.

CLASSIFICADOS. Livro Didático. Jornal do Brasil, 20 maio 1973, $3^{\circ}$ caderno, p. 12.

COLÉGIO MUNICIPAL PELOTENSE. Carta da Editora do Brasil ao Diretor Colégio Municipal Pelotense. Acevo Museu do Colégio Municipal Pelotense.

COLUNA ENTRE UMAS E OUTRAS. Diário do Paraná, 5 mar. 1972, terceiro caderno, p. 5 .

DA IDEIA ORIGINAL À LIVRARIA. Folha de São Paulo, 7 out. 1973, segundo caderno, Educação, p. 20.

EDITOR acha prejudicial à classe atuação do INL na produção do livro didático. Jornal do Brasil, 17 mar. $1974,1^{\circ}$ caderno, p. 26. 
FERREIRA, Idalina Ladeira. Cartilha Arco-Íris: processo ativo de alfabetização rápida. São Paulo: Saraiva, 1976.

HALLEWELL, Laurence. O livro no Brasil: sua história. São Paulo: USP, 1985.

INL DEVE encerrar amanhã a fase dos contratos de coedição de livro didático. Jornal do Brasil. 09/10/1972, $1^{\circ}$ Caderno, p. 4. Acervo Hemeroteca Digital Brasileira.

LIVRO. O Estado de Mato Grosso. 18/04/1974, p. 2. Acervo Hemeroteca Digital Brasileira.

LIVRO didático: 50 milhões de exemplares. Jornal do Brasil. 27/02/1971, Livro Suplemento do Jornal do Brasil, p. 1. Acervo Hemeroteca Digital Brasileira.

LIVRO didático para ensino reformado é exposto por 12 editoras em pré-lançamento. Jornal do Brasil. 19 e 20/12/1971, $1^{\circ}$ Caderno, p. 23. Acervo Hemeroteca Digital Brasileira. MAGALHÃES, Mauro. Revolução no livro didático - capítulo II. Diário de Notícias. 08/11/1975, p. 6. Acervo Hemeroteca Digital Brasileira.

MAGALHÃES, Mauro. Revolução no livro didático - capítulo VII. Diário de Notícias. 12/12/1975, p. 6. Acervo Hemeroteca Digital Brasileira.

MAGALHÃES, Mauro. Revolução no livro didático - capítulo VIII. Diário de Notícias. por Mauro Magalhães. 19/12/1975, p. 6. Acervo Hemeroteca Digital Brasileira.

MEC/INL. Catálogo das coedições do Instituto Nacional do Livro (1971-1974). Brasília, 1974. Acervo Biblioteca UnB.

MEC/INL. Catálogo do Instituto Nacional do Livro (1974-1975). Brasília, 1976. Acervo CIBEC/INEP.

MEC/INL. Programa Nacional do Livro Didático. Brasília, 1973. Acervo CIBEC/INEP.

NEI Braga abre reunião sobre livro. Jornal do Brasil. 14/04/1975, $1^{\circ}$ Caderno, p. 14. Acervo Hemeroteca Digital Brasileira.

OLIVEIRA, João Batista Araújo; GUIMARÃES, Sonia Dantas Pinto Guimarães e BOMÉNY, Helena Maria Bousquet. A política do livro didático. São Paulo: Summus; Campinas: Unicamp, 1984.

PEQUENAS fichas. Veja. 05/12/1973, edição 274, p. 74. Acervo digital Veja.

PONTO final. Diário de Notícias. 23/05/1973, p. 5. Acervo Hemeroteca Digital Brasileira.

RAZZINI, Marcia de Paula Gregório. Produção de livros didáticos e expansão escolar em São Paulo (1889-1930). CONGRESSO LUSO-BRASILEIRO DE HISTÓRIA DA EDUCAÇÃO, 6, 2006. Anais ... Uberlândia: UFU/SBHE, 2006.

RAZZINI, Marcia de Paula Gregório. São Paulo: cidade dos livros escolares. In: BRAGANÇA, Anibal; ABREU, Márcia (org.). Impresso no Brasil: dois séculos de livros brasileiros. São Paulo: Unesp, 2010, p. 101-120.

SOARES, Gabriela Pellegrino. Os irmãos Weiszflog em busca dos mercados escolares: identidades das Edições Melhoramentos dos primórdios à deca de 1960. In: BRAGANÇA, Anibal; ABREU, Márcia (org.). Impresso no Brasil: dois séculos de livros brasileiros. São Paulo: Unesp, 2010, p. 157-169.

THOMPSON, John B. Mercadores de cultura. São Paulo: Unesp, 2013. 
MÔNICA MACIEL VAHL é doutoranda em Educação na University of Canterbury, mestre em Educação pela Universidade Federal de Pelotas.

Endereço: 2/89a Peverel Street, Riccarton - Christchurch - New Zealand - 8041.

E-mail: monicamvahl@gmail.com.

ELIANE PERES é professora na Faculdade de Educação da Universidade Federal de Pelotas, doutora em Educação pela Universidade Federal de Minas Gerais.

Endereço: Faculdade de Educação da UFPel - Rua Alberto Rosa, 154 - 96010-770 Pelotas - RS - Brasil.

E-mail: eteperes@gmail.com.

Recebido em 2 de fevereiro de 2016.

Aceito em 17 de junho de 2016. 